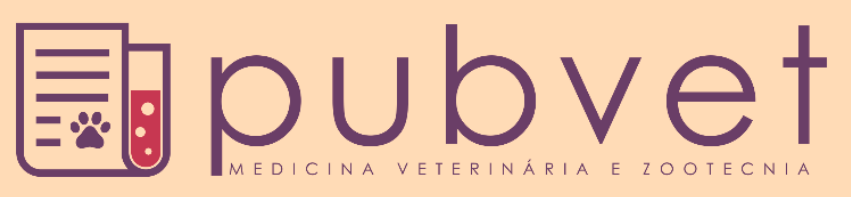

https://doi.org/10.31533/pubvet.v15n11a951.1-6

\title{
Protocolo pós-exposição ao vírus da Cinomose canina, com vacina de alta carga viral: Estudo observacional
}

\author{
Yohhane Tracy Hofmann Nascimento ${ }^{1} \bullet$, Rodrigo Antonio Martins de Souza ${ }^{2}$, Meire Christina \\ $\operatorname{Seki}^{2}{ }^{\circ}$, Adriano de Oliveira Torres Carrasco ${ }^{\circ} 2^{*}$ \\ ${ }^{1}$ Pós-graduanda da Universidade de São Paulo, Departamento de Patologia. São Paulo, SP, Brasil. \\ ${ }^{2}$ Professor na Universidade Estadual do Centro-Oeste do Paraná, Departamento de Medicina Veterinária Guarapuava-PR \\ *Autor para correspondência, E-mail: adriano.carrasco@gmail.com
}

\begin{abstract}
Resumo. A Cinomose canina é uma doença infectocontagiosa causada por um Morbillivirus, o qual pode se manifestar nos animais de forma respiratória e ocular, gastroentérica, neurológica e cutânea. O vírus atinge cães de qualquer sexo, idade e raça. É uma doença viral facilmente prevenida através da vacinação anual realizada com vacina polivalente canina (WSAVA, 2015). Foram atendidos na Clínica Escola de Veterinária Prof. Marcos Vinicius Tranquilim entre março de 2018 a fevereiro de 2020, 113 cães com suspeita clínica de Cinomose. Alguns animais possuíam contactantes em seu domicílio e foi instituído um protocolo de vacinação pós-exposição. Dos 25 contactantes que foram vacinados, nenhum apresentou sinal clínico de Cinomose, validando, desta forma, o protocolo de vacinação pós-exposição.
\end{abstract}

Palavras chave: Canis lupus familiaris, CDV, morbillivirus, NOBIVAC ${ }^{\circledR}$ PUPPY DP

\section{Protocol after exposure to the canine distemper virus, with high viral load vaccine: Observational study}

\begin{abstract}
Canine distemper is an infectious disease caused by a Morbillivirus, and it can manifest itself in animals in a respiratory and ocular, gastroenteric, neurological and cutaneous form. The virus affects dogs of any sex, age and breed. It is a viral disease easily prevented through the annual vaccination performed with a recombinant vaccine (WSAVA, 2015). Were attended in school veterinarian clinic Marcos Vinicius Tranquilim between March 2018 and February 2020, 113 dogs with clinical suspicion of Distemper. Some animals had contacts at home and were instituted in a post-exposure vaccination protocol. Of the 25 contacts that were vaccinated, there was no clinical sign of distemper, thus validating the post-exposure vaccination protocol.
\end{abstract}

Keywords: Canis lupus familiaris, CDV, Morbillivirus, Nobivac ${ }^{\circledR}$ Puppy DP.

\section{Protocolo después de la exposición al virus de moquillo canino, con la vacuna de alta carga viral: Estudio observacional}

Resumen. El moquillo canino es una enfermedad infecciosa causada por un Morbillivirus, que puede manifestarse en animales en forma respiratoria y ocular, gastroenterica, neurológica y cutánea. El virus afecta a perros de cualquier sexo, edad y raza. Es una enfermedad viral que se puede prevenir fácilmente mediante la vacunación anual realizada con la vacuna polivalente canina (WSAVA, 2015). Fueron atendidos en la Clínica Escuela Veterinaria Prof. Marcos Vinicius Tranquilim entre marzo de 2018 y febrero de 2020, 113 perros con sospecha clínica de Moquillo. Algunos animales tenían contactos en casa y se 
instituyó un protocolo de vacunación posterior a la exposición. De los 25 contactos que fueron vacunados, ninguno mostró signos clínicos de moquillo, validando así el protocolo de vacunación posterior a la exposición.

Palabras clave: Canis lupus familiaris, CDV, Morbillivirus, Nobivac ${ }^{\circledR}$ Puppy DP

\section{Introdução}

A Cinomose canina é uma doença viral causada por um vírus RNA com envoltório, pertencente ao gênero Morbillivirus canino e a família Paramyxoviridae (Catroxo, 2003; Nascimento, 2009). A Cinomose afeta predominantemente carnívoros, sendo de grande importância na clínica de pequenos animais (Beineke et al., 2009).

O agente pode afetar cães de qualquer idade, sendo que a apresentação clínica da enfermidade está relacionada à ausência de resposta imune prévia contra a Cinomose. Desta forma, a fase clínica tem maior ocorrência em cães de três a seis meses de idade, devido a uma queda dos anticorpos colostrais, além de animais idosos e imunossuprimidos. Os cães se infectam principalmente ao entrar em contado com secreções/excreções respiratórias proveniente de animais infectados, sendo que a excreção de partículas virais pode iniciar em torno de sete dias após a infecção, na fase assintomática, e perdurar cerca de até quatro meses de forma intermitente. É um agente que apresenta uma alta morbidade, se disseminando rapidamente dentro de um grupo de animais (Greene \& Vandevelde, 2015; Shell, 1990).

Os sinais clínicos dependem da virulência da estirpe, condições ambientais, idade e status imunológico, sendo que os sistemas respiratório, gastrointestinal e neurológico, são os mais afetados (Duque-Valencia et al., 2019; Nardo et al., 2020). O vírus infecta diferentes tecidos, entre eles o tecido epitelial, mesenquimal, neuroendócrino e hematopoiético, produzindo assim sinais clínicos mais comuns como secreção nasal e ocular, erupções cutâneas, êmese e diarreia, leucoencefalomielite desmielinizante e a função imunológica do animal fica comprometida, devido a perda de linfócitos associada à replicação viral (Beineke et al., 2009; Nardo et al., 2020; Ribeiro et al., 2020).

O diagnóstico da doença pode ser presuntivo, de acordo com os sinais clínicos apresentados, levando em consideração o histórico da doença no local em que o animal vive, já que muitas vezes a mioclonia é único sinal que este apresenta. Além de uma minuciosa avaliação clínica, podem ser associados exames laboratoriais como provas de biologia molecular, como a RT-PCR, que faz a detecção do material genético viral. Da mesma forma, testes de imunocromatografia, para a detecção direta, ou mesmo exames sorológicos como a RIFI e teste de ELISA, para a detecção de anticorpos, podem ser utilizados (Martella et al., 2008). Contudo, neste caso, o animal pode vir a óbito antes da produção desses anticorpos, o que é um limitador da técnica (Martella et al., 2008). O animal infectado também pode apresentar algumas alterações hematológicas, as quais podem ser indicativas da doença, como a presença de linfopenia, em uma fase inicial da enfermidade (Alfieri et al., 2006).

O tratamento geralmente é sintomático, podendo ser feito o uso de antimicrobianos para tratar ou evitar infecção bacteriana secundária, expectorantes, anti-inflamatórios, dependendo do caso pode ser feito o uso de anticonvulsivantes e auxiliar na melhora da imunidade com uso de complexo vitamínico e alimentação adequada (Greene \& Vandevelde, 2015). A doença é facilmente prevenida por imunização com uso de vacinas, desinfecção das instalações e isolamento de animais infectados.

Este trabalho teve por objetivo avaliar a eficácia do protocolo de imunização pós-exposição com vacina de alta massa viral, em cães não vacinados, em situação de risco devido ao contato com cães apresentando sinais clínicos de Cinomose.

\section{Material e métodos}

Foram atendidos na Clínica Escola Veterinária Prof. Marcos Vinicius Tranquilim, entre março de 2018 a fevereiro de 2020, 113 animais com suspeita de Cinomose canina. Destes animais, 50 não eram vacinados e 44 não sabiam informar sobre histórico de vacinação, 12 animais estavam com as vacinas desatualizadas e 7 haviam recebido vacina de forma não ética, aplicada por leigos, sem a supervisão de Médico Veterinário. A idade dos animais variava, sendo que 18 eram cães filhotes de até 1 ano, 23 tinham entre 1 até 5 anos, 15 animais tinham entre 6 e 10 anos, três animais tinham mais de 10 anos e 
54 animais eram adultos e os tutores não sabiam informar a idade. O grupo de animais com apresentação clínica era de 60 fêmeas e 53 machos.

Os animais não foram submetidos a nenhuma experimentação, ou a procedimentos invasivos. Foi efetuado um estudo observacional, com base na necessidade de imunização e/ou de atendimento Veterinário, avaliando protocolos utilizados em rotina, com base apenas no acompanhamento das fichas clínicas.

Dos 113 animais avaliados, 61,95\% (70/113) foram submetidos a teste de imunocromatografia para detecção do antígeno do Vírus da Cinomose, e os 38,05\% (43/113) dos animais restantes, por ausência de recursos por parte dos tutores, não foram testados e foram tratados apenas com base nos sinais clínicos, sem a realização de exames complementares.

Os animais eram tratados conforme os sinais clínicos que apresentavam, com uso de antiinflamatório esteroidal, antimicrobianos, multivitamínicos e quando necessários era feito uso de colírios e anticonvulsivantes.

Dos animais atendidos, 17,7\% (20/113) vieram a óbito em decorrência da doença e em $27,4 \%$ (31/113) deles, foi realizada a eutanásia por orientação do Médico Veterinário e concordância por parte do tutor, decorrente da evolução clínica do caso. Alguns animais não retornaram para avaliação e acompanhamento. Os animais que foram devidamente tratados, posteriormente foram vacinados, assim como os contactantes que conviviam no mesmo ambiente.

A vacina de escolha para estes animais era a NOBIVAC ${ }^{\circledR}$ PUPPY DP, e após 21 dias era realizado um reforço vacinal com a dose de vacina NOBIVAC ${ }^{\circledR} \mathrm{DHPPi}+\mathrm{L}$, já que a primeira conta apenas o imunizante do vírus da Parvovirose canina e do vírus da Cinomose canina, na intenção de possibilitar uma maior intensidade de resposta imune, enquanto a segunda contempla imunizantes contra mais cinco doenças, de acordo com recomendações do fabricante.

Foram vacinados 13 animais, dentre aqueles que se recuperaram da apresentação clínica da Cinomose, além de 25 cães contactantes, totalizando 38 animais. Antes da vacinação, os animais eram submetidos à anamnese e exame físico, eram realizados também exames coproparasitológicos para verificar a necessidade do uso de antiparasitários.

Dos animais recuperados, 8 nunca haviam recebido nenhuma dose de vacina e 1 não possuía histórico, 1 cão estava com as vacinas atrasadas e 1 recebeu vacina de forma não ética, enquanto dos contactantes, 24 nunca haviam sido vacinados e 1 animal estava com as vacinas desatualizadas.

\section{Resultados e discussão}

Todos os animais atendidos com suspeita de portar o vírus da Cinomose Canina apresentavam algum sinal clínico compatível com a enfermidade, a saber: secreção ocular e/ou nasal, distúrbios gastrointestinais, alterações neurológicas, ataxia, pústulas em região abdominal, hipoplasia de esmalte dentário, entre outros. $\mathrm{Na}$ anamnese, o principal relato foi que estes animais não eram vacinados, estavam com a vacinação atrasada ou ainda o próprio proprietário ou um leigo havia aplicado a vacina, sem a supervisão de um Médico Veterinário.

Segundo as diretrizes da WSAVA (2015) que é a Associação Mundial de Veterinários de Pequenos Animais, as vacinas são divididas em vacinas essenciais, que são aquelas vacinas que todos os cães no mundo inteiro devem receber, seguindo os intervalos recomendados, sendo elas as vacinas contendo antígenos para Cinomose canina (CDV), adenovírus canino (CAV, tipo 1 e 2) e parvovírus canino tipo 2 (CPV-2) e também incluindo suas variantes, vacinas não essenciais e vacinas não recomendadas.

O WSAVA (2015) separa as vacinas em infecciosas, que são as vacinas atenuadas ou com vírus vivo modificado (VVM), este tipo de vacina induz imunidade causando um baixo nível de infecção e assim produzindo os anticorpos específicos, as vacinas recombinantes também são consideradas infecciosas, possuindo um vetor que possui material genético capaz de codificar o antígeno do patógeno que se deseja imunidade. As vacinas não infecciosas, também conhecidas como vacinas inativadas/mortas, não são capazes de infectar o animal e necessitam de um adjuvante para potencializar seu efeito, esse tipo de vacina, geralmente requer várias doses, sendo menos eficaz que a vacina infecciosa. 
Atualmente existe um novo tipo de vacina, a de alta massa viral, a qual é considera dez vezes mais potente que as vacinas atenuadas encontradas no mercado e tem demonstrado sucesso na imunização em locais de risco e para raças sensíveis (Zakrzewski, 2003).

Por se tratar de um vírus com alto índice de morbidade e mortalidade, é possível que os contactantes expostos possam ter entrado em contato com o vírus, visto que a eliminação viral pelo hospedeiro pode ocorrer antes mesmo destes apresentarem sinais clínicos, contudo, o fato de terem sido imunizados com uma vacina de alta carga viral, sendo esta uma vacina viva atenuada, não permitiu que o vírus se instalasse no organismo desses animais (Greene \& Vandevelde, 2015; Zakrzewski, 2003).

Dos 25 contactantes vacinados com a vacina NOBIVAC ${ }^{\circledR}$ PUPPY DP, nenhum apresentou sinal clínico da doença, permanecendo todos em bom estado geral dentro do período de 21 a 30 dias, após o início do protocolo de exposição, para o reforço vacinal, indicando eficácia do protocolo pós-exposição escolhido (Figura 1).

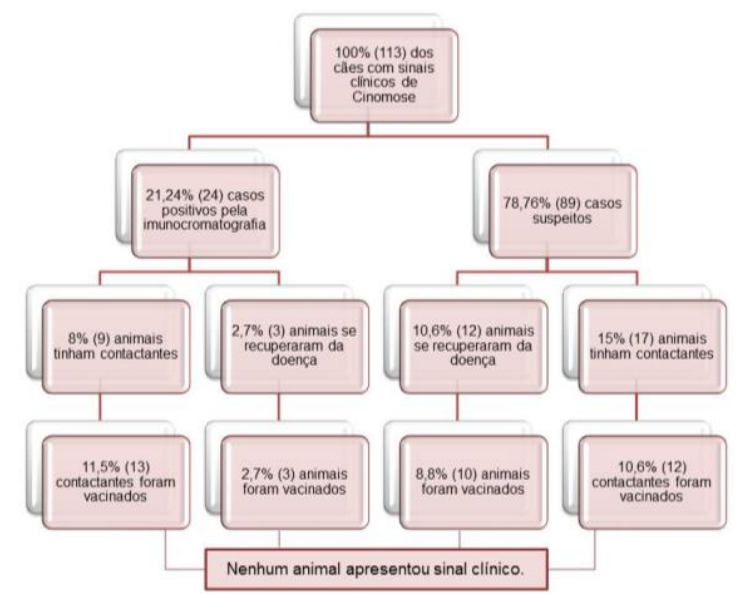

Figura 1. Relação de animais com contactantes e animais vacinados, conforme o diagnóstico por imunocromatografia ou somente pelo diagnóstico clínico da Cinomose.

O estado do animal no momento da vacinação é de suma importância para um protocolo bem sucedido. Romiszewski et al. (2018) em um estudo em que protocolos vacinais em animais com inflamação subclínica apresentaram baixa produção de anticorpos, fazendo assim com que a duração da vacina fosse menor que o esperado.

As principais vias de transmissão se dão por locais com superlotação de animais nos quais há estresse e consequentemente baixa na imunidade, como canis, clínicas, criadouros, pela via transplacentária da mãe dos filhotes, falhas vacinais independentemente da causa e por conta da taxa de animais infectados ser maior que o número de animais com doença clínicas, todos esses são fatores de disseminação do vírus na população suscetível (Portela et al., 2017).

Cães com sinais gastrointestinais ou respiratórios devem ser isolados, devido ao fato de que contaminam animais suscetíveis através de aerossóis, já que as secreções (fezes, secreção ocular, secreção nasal, saliva, urina, etc.) estão contaminadas com partículas virais, deve-se também tomar cuidado com fômites contaminados como fonte de transmissão da doença (DiGangi et al., 2019; Nelson \& Couto, 2015).

O contato dos animais infectados, seja de forma clínica ou subclínica, com animais suscetíveis facilita a disseminação do vírus, visto que o mesmo possui alta infectividade e atinge qualquer faixa etária, por isso o isolamento é tão importante (Greene \& Vandevelde, 2015).

A vacinação de cães domésticos também tem sido justificada como um meio de conservação da vida selvagem, com a inferência de que a ocorrência de doenças transmissíveis, principalmente a Cinomose, na população canina doméstica tem o potencial de afetar a carga de doenças na vida selvagem, incluindo felídeos selvagens e canídeos selvagens. Isso demonstra que o índice de transmissão é tão alto que pode afetar seriamente a vida selvagem, já que a transmissão não acorre apenas por contato direto, mas 
também por fluídos corporais. Portando, locais com a presença do patógeno permitem facilmente a transmissão a animais não vacinados (Thompson et al., 2020).

A vacinação ainda é o melhor meio para a prevenção da Cinomose canina e as falhas vacinais geralmente estão associados a um protocolo vacinal incorreto ou alteração da vacina após armazenamento de forma inadequado, por isso o papel do médico veterinário é tão importante para a prevenção dessa doença (Martella et al., 2008). Desta forma, reforça a necessidade de avaliação por um Médico Veterinário, no momento da realização de um programa de imunização.

Martella et al. (2008), Panzera et al. (2012), Anis et al. (2018) e Duque-Valencia et al. (2019) associaram a circulação de diferentes estirpes do vírus da Cinomose a possíveis falhas vacinais e enfatizaram a importância da vacinação realizada de forma adequada e acompanhamento do paciente. Vila Nova et al. (2018) enfatizaram que tanto a Cinomose quanto a Parvovirose causam infecções com alta taxa de letalidade, pois ambos os agentes afetam cães não vacinados ou com protocolos vacinais incompletos, portanto a vacinação é de suma importância para reduzir o índice da doença e controlar a disseminação do vírus.

Zakrzewski (2003) demonstrou em seu dossiê, que em duas ocasiões o componente CDV da vacina NOBIVAC ${ }^{\circledR}$ PUPPY DP foi mais adequado para a vacinação de filhotes que outras vacinas, conferindo assim, maior produção de anticorpos. A escolha da vacina NOBIVAC ${ }^{\circledR}$ PUPPY DP se deu pelas características da vacina, visto que a mesma além de ser a única vacina passível de ser administrada a partir de 28 dias de idade, a fração de massa viral contra o vírus da Cinomose é dez vezes maior que de outras vacinas disponíveis no mercado e causa imunidade estéril, evitando que os animais vacinados possam servir como fonte de infecção para outros animais.

\section{Conclusão}

O protocolo pós-exposição realizado com a vacina de vírus vivo atenuado e alta carga viral NOBIVAC ${ }^{\circledR}$ PUPPY DP, se mostrou eficaz em 100\% dos animais vacinados, indicando a sua utilização para prevenção da Cinomose canina e evitar a disseminação do vírus na população suscetível.

\section{Referências bibliográficas}

Alfieri, A. F., Amude, A. M., \& Alfier, A. A. (2006). The nervous form of canine distemper. Veterinária e Zootecnia, 13(2), 125-136. https://doi.org/10.35172/rvz.2006.v13.258.

Anis, E., Holford, A. L., Galyon, G. D., \& Wilkes, R. P. (2018). Antigenic analysis of genetic variants of canine distemper virus. Veterinary Microbiology, 219, 154-160. https://doi.org/10.1016/j.vetmic.2018.07.020.

Beineke, A., Puff, C., Seehusen, F., \& Baumgärtner, W. (2009). Pathogenesis and immunopathology of systemic and nervous canine distemper. Veterinary Imunology and Immunopathology, 127(1-2), 118. https://doi.org/10.1016/j.vetimm.2008.09.023.

Catroxo, M. H. B. (2003). Cinomose canina. Arquivo Do Instituto Biológico de São Paulo, 65(1/2), 1-2.

DiGangi, B. A., Dingman, P. A., Grijalva, C. J., Belyeu, M., Tucker, S., \& Isaza, R. (2019). Prevalence and risk factors for the presence of serum antibodies against canine distemper, canine parvovirus, and canine adenovirus in communities in mainland Ecuador. Veterinary Immunology and Immunopathology, 218, 109933. https://doi.org/10.1016/j.vetimm.2019.109933.

Duque-Valencia, J., Sarute, N., Olarte-Castillo, X. A., \& Ruíz-Sáenz, J. (2019). Evolution and interspecies transmission of canine distemper virus-An outlook of the diverse evolutionary landscapes of a multi-host virus. Viruses, 11(7), 582. https://doi.org/10.3390/v11070582.

Greene, C. E., \& Vandevelde, M. (2015). Cinomose. In C. E. Greene (Ed.), Doenças infecciosas em cães e gatos. Guanabara Koogan.

Martella, V., Elia, G., \& Buonavoglia, C. (2008). Canine distemper virus. Veterinary Clinics of North America: Small Animal Practice, 38(4), 787-797. https://doi.org/10.1016/j.cvsm.2008.02.007.

Nardo, T. F. S., Bertolo, P. H. L., Bernardes, P. A., Munari, D. P., Machado, G. F., Jardim, L. S., Moreira, P. R. R., Rosolem, M. C., \& Vasconcelos, R. O. (2020). Contribution of astrocytes and macrophage migration inhibitory factor to immune-mediated canine encephalitis caused by the 
distemper virus. Veterinary Immunology and Immunopathology, 221, 110010. https://doi.org/10.1016/j.vetimm.2020.110010.

Nascimento, D. N. S. (2009). Cinomose Canina-Revisão de Literatura (pp. 1-34).

Nelson, R. W., \& Couto, C. G. (2015). Medicina interna de pequenos animais (Issue 1). Elsevier Editora.

Panzera, Y., Calderón, M. G., Sarute, N., Guasco, S., Cardeillac, A., Bonilla, B., Hernández, M., Francia, L., Bedó, G., \& La Torre, J. (2012). Evidence of two co-circulating genetic lineages of canine distemper virus in South America. Virus Research, 163(1), 401-404. https://doi.org/10.1016/j.virusres.2011.10.008.

Portela, V. A. B., Lima, T. M., \& Maia, R. C. C. (2017). Cinomose canina: revisão de literatura. Medicina Veterinária (UFRPE), 11(3), 162-171.

Ribeiro, A. I. T., Burema, M. C., Borges, A. P. S., Bruno, V. C. M., Nespoli, P. E. B., Colodel, E. M., Gouvêa, F. H. F., Dutra, V., Nakazato, L., \& Ribeiro, M. G. (2020). Pyogranulomatous pleuropneumonia caused by Nocardia asiatica in a dog coinfected with canine morbillivirus (canine distemper virus). Veterinary Medicine and Science, 6(1), 25-31. https://doi.org/10.1002/vms3.202.

Romiszewski, P., Kostro, K., \& Lisiecka, U. (2018). Effects of subclinical inflammation on C-reactive protein and haptoglobin levels as well as specific humoral immunity in dogs vaccinated against canine distemper and parvovirus. BMC Veterinary Research, 14(1), 1-6. https://doi.org/10.1186/s12917-018-1383-6.

Shell, L. G. (1990). Canine distemper. Companie Small Animal, 12, 173-179.

Thompson, R., Adams, H., Odoi, A., \& Kennedy, M. (2020). Seroprevalence of viral and vector-borne bacterial pathogens in domestic dogs (Canis familiaris) in northern Botswana. PloS One, 15(1), e0220593. https://doi.org/10.1371/journal.pone.0220593.

Vila Nova, B., Cunha, E., Sepúlveda, N., Oliveira, M., São Braz, B., Tavares, L., Almeida, V., \& Gil, S. (2018). Evaluation of the humoral immune response induced by vaccination for canine distemper and parvovirus: A pilot study. BMC Veterinary Research, 14(1), 1-8. https://doi.org/10.1186/s12917-018-1673-z.

Zakrzewski, B. (2003). Progran NOBIVAC. Magazyn Weterynaryjny, 12(6), 51-52.

WSAVA. Guidelines of vaccination of dogs and cats. 2015. Disponível em: <https://wsava.org/globalguidelines/vaccination-guidelines/> Acesso em: 10 de fevereiro de 2020.

Histórico do artigo:

Recebido: 2 de maio de 2021

Aprovado: 4 de junho de 2021
Licenciamento: Este artigo é publicado na modalidade Acesso Aberto sob a licença Creative Commons Atribuição 4.0 (CC-BY 4.0), a qual permite uso irrestrito, distribuição, reprodução em qualquer meio, desde que o autor e a fonte sejam devidamente creditados. 